\title{
Elodie Carine Tang, Le roman féminin francophone de la migration. Émergence et identité
}

\section{Carminella Biondi}

\section{(2) OpenEdition}

1 Journals

\section{Edizione digitale}

URL: http://journals.openedition.org/studifrancesi/4494

DOI: 10.4000/studifrancesi.4494

ISSN: 2421-5856

\section{Editore}

Rosenberg \& Sellier

\section{Edizione cartacea}

Data di pubblicazione: 1 settembre 2016

Paginazione: 373

ISSN: 0039-2944

\section{Notizia bibliografica digitale}

Carminella Biondi, «Elodie Carine Tang, Le roman féminin francophone de la migration. Émergence et identité », Studi Francesi [Online], 179 (LX | II) | 2016, online dal 01 septembre 2016, consultato il 18 septembre 2020. URL : http://journals.openedition.org/studifrancesi/4494 ; DOI : https://doi.org/ 10.4000/studifrancesi.4494

Questo documento è stato generato automaticamente il 18 settembre 2020.

\section{(c)}

Studi Francesi è distribuita con Licenza Creative Commons Attribuzione - Non commerciale - Non opere derivate 4.0 Internazionale. 


\title{
Elodie Carine Tang, Le roman féminin francophone de la migration. Émergence et identité
}

\author{
Carminella Biondi
}

\section{NOTIZIA}

ÉLODIE CARINE TANG, Le roman féminin francophone de la migration. Émergence et identité,

Paris, L'Harmattan, 2015, «Critiques littéraires», 239 pp.

1 Ancora prima di iniziare l'analisi del saggio è opportuno precisare che la portata del titolo va ampiamente ridimensionata. Il lavoro si limita a tre scrittrici migranti, anche se la lettura della loro opera può offrire spunti per un discorso di carattere generale, per il quale mancano però riferimenti critici importanti (fra gli altri un numero della rivista «Francofonia» del 2010, intitolato: Exilées, expatriées, migrantes...). Due delle scrittrici studiate sono di origine africana, Ken Bugul (pseudonimo di Mariétou Mbaye), camerunense e Léonora Miano, senegalese; la terza, Abla Faroud, è di origine libanese, anche se ha lasciato il suo paese all'età di sei anni (ma vi è ritornata spesso). Il paradigma critico adottato è, almeno in partenza, quello del "campo letterario" con riferimento ai lavori di Pierre Bourdieu, che solo con qualche sforzo si riesce ad applicare a queste scrittrici, come in genere agli scrittori migranti, i quali, almeno negli ultimi tempi, preferiscono collocarsi nel "non luogo" dell'erranza o in quello altrettanto vago della "littérature-monde". Il che non significa, come viene sottolineato nella prima parte del saggio, intitolata "État des champs africain et québécois et trajectoire des écrivaines» (pp. 11-72), che non emerga nelle opere di queste scrittrici il rapporto problematico con il campo letterario di partenza e di arrivo, una problematicità che è all'origine della loro crisi identitaria, sia pure manifestata in forme diverse, e in genere di tutte le scritture migranti, di cui questa crisi sarebbe proprio la cifra: «Ken Bugul, Léonora Miano et Abla Faroud ont eu des parcours dans lesquels elles ressentaient un malaise, quelque peu confus au départ, mais qui par la 
suite va se révéler comme un malaise identitaire [...]. Aucune d'elle n'a d'ancrage nulle part, tiraillées entre l'ancrage et l'errance» (p. 71). Anche se poi la Tang dovrà riconoscere che la volontà degli autori di sottrarsi all'appartenenza a un campo letterario specifico è una delle caratteristiche della scrittura contemporanea, che trova il suo punto di emergenza nelle scritture della diaspora.

2 Nella seconda parte del saggio, intitolata «La déconstruction de la polarisation centripète» (pp. 73-160), la studiosa analizza in maniera più puntuale i nodi della crisi identitaria delle scrittrici: il sesso o genere, la religione, la politica, la famiglia, il rapporto con l'altro, sia nel paese di origine che in quello (o quelli) di arrivo: «La déconstruction de la polarisation centripète donne lieu à un dérèglement multiforme dont la finalité s'avère être la quête d'un renouveau social et littéraire, celle d'une appropriation/réappropriation identitaire» (p. 160).

Questa «quête» di una riappropriazione di sé è studiata nella terza parte: «Les enjeux sociaux, littéraires et institutionnels de l'appropriation/réappropriation identitaire» (pp. 161-223), in cui vengono seguiti i percorsi imboccati dalle tre scrittrici per uscire dallo stato di «malaise» che le opprime e analizzate le tecniche di scrittura adottate per comprendersi e nello stesso tempo per "comprendre la vie», al fine di trovarvi una propria collocazione non marginale $\mathrm{o}$, quantomeno, di una marginalità voluta $\mathrm{e}$ assunta. La via indubbiamente più originale e per certi versi stupefacente è quella percorsa da Ken Bugul che, per vivere senza conflitti interiori nella sua epoca, ha dovuto percorrere a ritroso un lungo cammino che l'ha riportata dall'Occidente al suo villaggio di origine, alla sua tribù, dove ha accettato di divenire la ventottesima moglie di un marabut di ottantacinque anni. Questa scelta arcaica le ha permesso, paradossalmente, di collocarsi in maniera meno conflittuale nella modernità.

4 Un saggio non privo di limiti, fra cui anche numerose ripetizioni e qualche parte scontata, che però è un utile strumento non solo per la conoscenza di tre grandi scrittrici della migrazione, ma anche per l'approfondimento delle tematiche legate a questo genere o, forse sarebbe meglio dire, a questo fenomeno letterario. 